\title{
Selective determination of 3,4-dihydroxyphenylacetic acid in the presence of ascorbic and uric acids using polymer film modified electrode
}

\author{
PALRAJ KALIMUTHU and S ABRAHAM JOHN* \\ Department of Chemistry, Gandhigram Rural University, Gandhigram 624 302, Dindigul, India \\ e-mail: abrajohn@yahoo.co.in
}

MS received 27 July 2010; accepted 3 November 2010

\begin{abstract}
We report here the highly sensitive and selective electrochemical determination of 3,4dihydroxyphenylacetic acid (DOPAC), one of the dopamine metabolites in the presence of important interferents ascorbic acid (AA) and uric acid (UA) using an ultrathin electropolymerized film of 5-amino-1,3,4thiadiazole-2-thiol (p-ATT) modified glassy carbon (GC) electrode in $0.20 \mathrm{M}$ phosphate buffer solution ( $\mathrm{pH}$ 5.0). The bare GC electrode fails to resolve the oxidation peaks of AA, DOPAC and UA in a mixture. Further, the oxidation peak potentials of them were shifted to more positive potential with decreased peak currents in the subsequent cycles. On the other hand, the p-ATT modified electrode not only separated the voltammetric signals of AA, DOPAC and UA but also enhanced their peak currents. The amperometric current response was increased linearly with increasing DOPAC concentration in the range of $4.0 \times 10^{-8}$ to $1.0 \times 10^{-5} \mathrm{M}$ and the detection limit was found to be $150 \mathrm{pM}(S / N=3)$.
\end{abstract}

Keywords. 5-Amino-1,3,4-thiadiazole-2-thiol; 3,4-dihydroxyphenylacetic acid; ascorbic acid; uric acid; amperometry.

\section{Introduction}

3,4-dihydroxyphenylacetic acid (DOPAC) is an important catabolite of dopamine (DA). ${ }^{1}$ The major pathway responsible for DA catabolism in the brain involves deamination by monoamine oxidase type $\mathrm{A}$ and $\mathrm{B}$ to form DOPAC, which is then converted to homovanillic acid (HVA) metabolite by $O$-methylation via the membrane bound and soluble forms of catecholamine$O$-methyltransferase. ${ }^{2}$ The DA metabolism can be assessed in the prefrontal cortex by measuring the extracellular levels of DOPAC. ${ }^{1,3-6}$ Therefore, the concentration of DOPAC is a sensitive indicator for neuronal functioning in nearby diencephalons structures. ${ }^{7}$ Usually, DOPAC exists as very low concentration along with AA and UA in blood serum and urine. ${ }^{8,9}$ Thus, the selective and sensitive determination of DOPAC is very important not only in the fields of biomedical chemistry and neurochemistry but also for diagnostic and pathological research. ${ }^{10}$ Several techniques have been used for the determination of DOPAC including electrochemical, ${ }^{11-19}$ high-performance liquid chromatography, ${ }^{20}$ chemiluminescence ${ }^{21}$ and fluorometry. ${ }^{22}$ Among these methods, electrochemical methods of detection

${ }^{*}$ For correspondence have attracted incessantly in recent years because they are more selective, sensitive and less time-consuming.

At unmodified electrodes, AA, DOPAC and UA were oxidized almost at the same potential and also they often suffered from the fouling effect due to the accumulation of oxidized products on the electrode surface, which resulted in rather poor selectivity and sensitivity. ${ }^{14}$ In order to avoid these problems, chemically modified electrodes have been employed for the selective and stable determination of DOPAC including poly $\left(N, N^{\prime}\right.$-dimethylaniline) modified boron-doped diamond electrode, ${ }^{11}$ short chain thiol/disulfides, ${ }^{12}$ 6-mercaptonicotinic acid, ${ }^{13}$ cationic self-assembled monolayer ${ }^{14}$ and gold nanoparticles immobilized on sol-gel network ${ }^{15}$ modified Au electrodes, nitrogendoped carbon nanotubes, ${ }^{16}$ single-wall carbon nanotubes ${ }^{17}$ and protein-polysaccharide hybrid modified GC electrodes ${ }^{18}$ and $\mathrm{TiO}_{2}$ nanostructured film modified silicon substrate. ${ }^{19}$

Although several reports have been published for the determination of DOPAC, fabrication of an electrochemical sensor with high sensitivity is still one of the challenging tasks for the researchers because the concentration of DOPAC present in our body fluids is very low $(3 \mathrm{nmol} / \mathrm{L}$ in the lumber cerebrospinal fluid and $60 \mathrm{nmol} / \mathrm{L}$ in the ventricular cerebrospinal fluid). ${ }^{23}$ 
Recently, we have prepared a nanostructured film of 5-amino-1,3,4-thiadiazole-2-thiol (ATT) by potentiodynamic method on GC electrode ${ }^{24}$ and demonstrated its excellent electrocatalytic properties toward L-cysteine, ${ }^{24}$ dopamine, ${ }^{25}$ folic acid, ${ }^{26}$ epinephrine ${ }^{27}$ and nitrite. ${ }^{28}$ Further to exploit the application of this polymer film, we have examined its electrocatalytic activity towards DA catabolite, DOPAC. It was found that the p-ATT modified electrode dramatically enhanced the DOPAC oxidation current nearly 1.5 fold higher with $80 \mathrm{mV}$ less positive potential when compared to bare GC electrode. Further, p-ATT film modified electrode showed an excellent selectivity toward the determination of DOPAC in the presence of 50-fold excess of AA and UA. Using amperometric method, we achieved the detection of $40 \mathrm{nM}$ and detection limit of $150 \mathrm{pM}(S / N=3)$ for DOPAC at p-ATT modified electrode.

\section{Experimental}

\subsection{Chemicals}

5-amino-1,3,4-thiadiazole-2-thiol (ATT), 3,4-dihydroxyphenylacetic acid (DOPAC), ascorbic acid (AA) and uric acid (UA) were purchased from Aldrich and were used as received. All other chemicals used in this investigation were of analytical grade. $\mathrm{pH} 5.0$ phosphate buffer (PB) solution was prepared using $\mathrm{Na}_{2} \mathrm{HPO}_{4}$ and $\mathrm{NaH}_{2} \mathrm{PO}_{4}$. Double distilled water was used to prepare the solutions used in this investigation.

\subsection{Instrumentation}

Electrochemical measurements were performed in a conventional two compartment, three electrode cell with a mirror polished $3 \mathrm{~mm}$ GC as the working electrode, $\mathrm{Pt}$ wire as counter electrode and a $\mathrm{NaCl}$ saturated $\mathrm{Ag} / \mathrm{AgCl}$ as reference electrode. The electrochemical measurements were carried out with CHI Model 643B (Austin, TX, USA) Electrochemical Workstation.

\subsection{Fabrication of p-ATT modified GC electrode}

Prior to modification, the GC electrode was polished with 0.50 and $0.05 \mu \mathrm{m}$ alumina slurries and rinsed thoroughly with water. Then, the electrode was sonicated in water for 5 minutes to remove the adsorbed alumina particles on the electrode surface. Electropolymerization of ATT on the GC electrode was carried out by 15 successive potential sweeps between -0.20 and
$+1.70 \mathrm{~V}$ at a scan rate of $50 \mathrm{mV} \mathrm{s}^{-1}$ in $1 \mathrm{mM}$ ATT containing $0.10 \mathrm{M} \mathrm{H}_{2} \mathrm{SO}_{4} \cdot{ }^{24}$ By this method, an ultrathin film of p-ATT with a thickness of $25 \mathrm{~nm}$ can be prepared on GC electrode. ${ }^{24}$

\section{Results and discussion}

\subsection{Electrochemical behaviour of DOPAC at bare and $p$-ATT modified GC electrodes}

The present electrochemical sensor was optimized in terms of thickness of the p-ATT film and $\mathrm{pH}$. The $\mathrm{p}$ ATT film deposited by 15 and 50 cycles, resulted in the thickness of $25 \mathrm{~nm}$ and $40 \mathrm{~nm}$, respectively. ${ }^{24}$ The p-ATT film deposited by 15 potential cycles showed higher electrocatalytic activity towards AA, DOPAC and UA than the films deposited by more than 15 potential cycles. Further, we have performed the redox reaction of DOPAC and oxidation of AA and UA at different $\mathrm{pH}$ using $\mathrm{p}$-ATT film. At $\mathrm{pH}$ 5.0, we observed higher oxidation currents for these analytes. Thus, in the present study, we have chosen the p-ATT film with a thickness of $25 \mathrm{~nm}$ and $\mathrm{pH} 5.0$ for the determination of AA, DOPAC and UA. Figure 1 shows the cyclic voltammograms (CVs) obtained for $0.50 \mathrm{mM}$ DOPAC at bare and p-ATT modified GC electrodes in $0.20 \mathrm{M}$

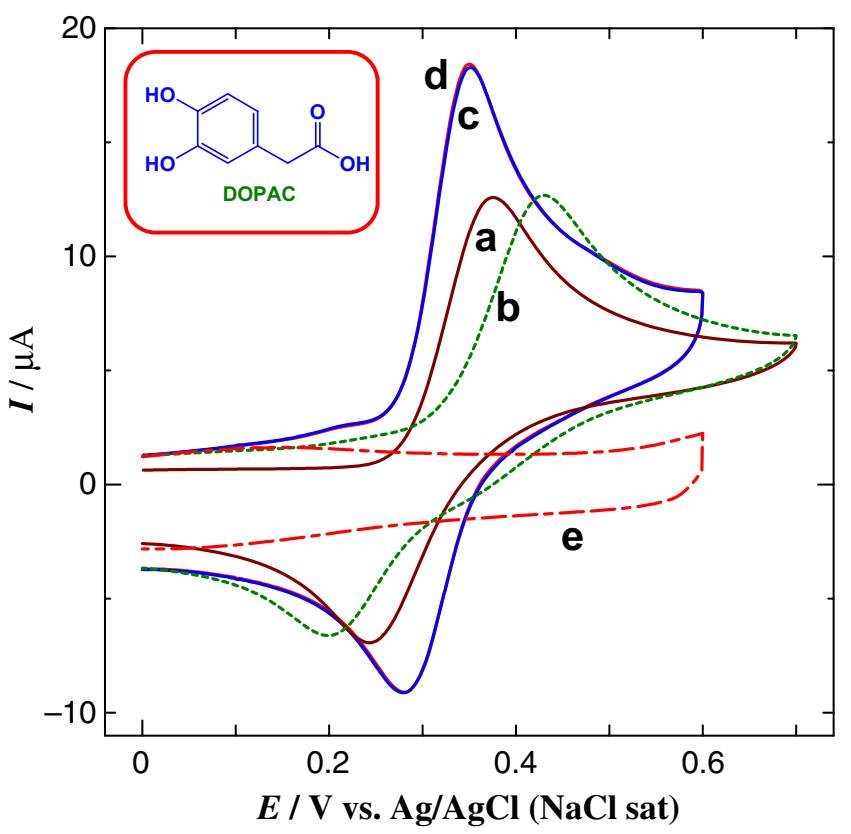

Figure 1. (a) CVs obtained for $0.50 \mathrm{mM}$ DOPAC at bare and p-ATT modified GC electrodes after $1^{\text {st }}$ (a and c) and $5^{\text {th }}$ (b and d) cycles in $0.20 \mathrm{M}$ PB solution ( $\mathrm{pH}$ 5.0) at a scan rate of $50 \mathrm{mV} \mathrm{s}^{-1}$. (e) $\mathrm{CV}$ obtained for $\mathrm{p}$-ATT modified electrode in $0.20 \mathrm{M}$ PB solution. Inset: Structure of 3,4-dihydroxyphenylacetic acid (DOPAC). 
PB solution ( $\mathrm{pH}$ 5.0). At bare GC electrode, oxidation and reduction peaks were observed for DOPAC at $0.38 \mathrm{~V}$ and $0.24 \mathrm{~V}$, respectively with a peak to peak separation of $140 \mathrm{mV}$ in the first cycle (curve a). The oxidation peak was shifted to more positive potential whereas the reduction peak was shifted to less positive potential in the subsequent cycles. After 5 cycles, the oxidation and reduction peaks were observed at $0.43 \mathrm{~V}$ and $0.20 \mathrm{~V}$, respectively with a peak to peak separation of $230 \mathrm{mV}$ (curve b). In addition, the reduction peak current was slightly decreased while the oxidation peak current remained same. The observed $230 \mathrm{mV}$ peak to peak separation suggests that the redox reaction of DOPAC is sluggish at bare GC electrode. However, a well-defined redox peak as well as enhanced electrochemical response was observed for DOPAC at p-ATT modified electrode with a peak to peak separation of $70 \mathrm{mV}$ (curve c). This revealed that the redox reaction of DOPAC was very much faster at p-ATT modified electrode than at bare GC electrode. It showed an oxidation and reduction peaks for DOPAC at $0.35 \mathrm{~V}$ and $0.28 \mathrm{~V}$, respectively. When compared to bare GC electrode, nearly 1.5 -fold higher oxidation peak current with $80 \mathrm{mV}$ less positive potential shift was observed for DOPAC at p-ATT modified electrode. Further, the redox peak of DOPAC is very much stable at p-ATT modified electrode in the subsequent cycles as evidenced from curve $d$. The observed redox peak corresponds to two-electron oxidation of DOPAC to DOPAC $o$-quinone and the subsequent reduction of DOPAC $o$-quinone to DOPAC. ${ }^{17}$ The p-ATT film does not show any pronounced electrochemical response between $0 \mathrm{~V}$ and $0.60 \mathrm{~V}$ in $0.20 \mathrm{M}$ PB solution (curve e).

The effect of scan rate on the redox reaction of DOPAC was studied at p-ATT modified electrode. The redox peak current of DOPAC was increased while increasing the scan rate (figure S1 in the Supporting information). A good linearity between the anodic peak current and square root of scan rate was obtained within the range from 50 to $1000 \mathrm{mV} \mathrm{s}^{-1}$ for DOPAC with a correlation coefficient of 0.9965 as shown in inset of figure S1 in the Supporting information. This indicated that the electrode reaction process is controlled by the diffusion of DOPAC.

\subsection{Electrochemical behaviour of AA, DOPAC and UA} in a mixture at bare and $p$-ATT modified GC electrodes

Figure 2 displays the linear sweep voltammograms (LSVs) obtained for $0.50 \mathrm{mM} \mathrm{AA}$, DOPAC and UA

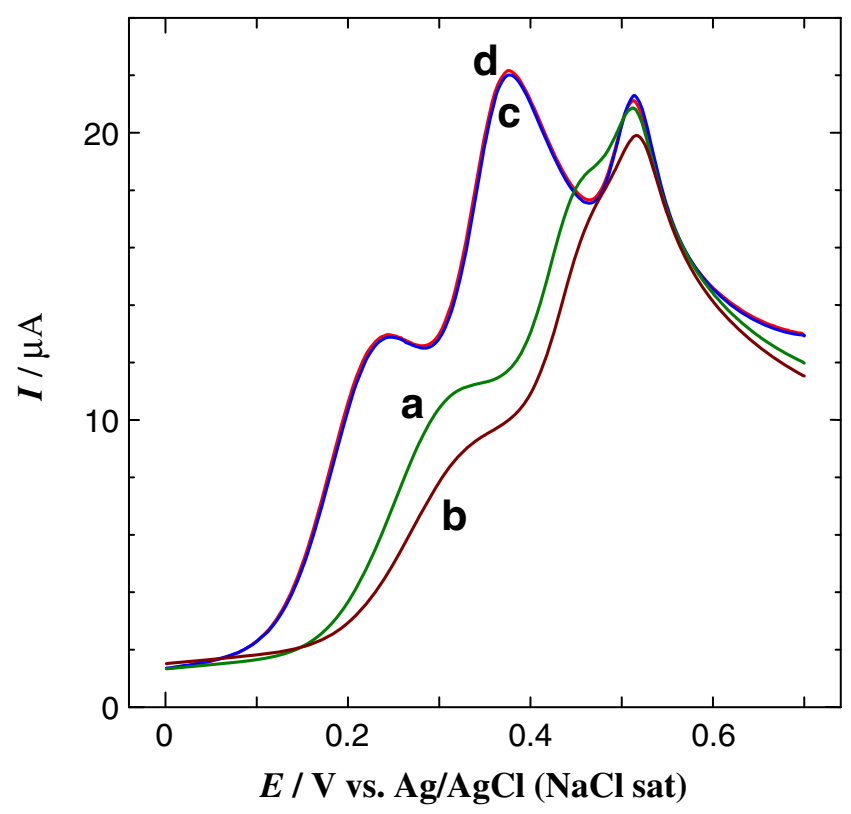

Figure 2. LSVs obtained for $0.50 \mathrm{mM}$ each AA, DOPAC and UA at bare and p-ATT modified GC electrodes after $1^{\text {st }}$ (a and c) and $5^{\text {th }}(\mathrm{b}$ and $\mathrm{d})$ cycles in $0.20 \mathrm{M}$ PB solution at a scan rate of $50 \mathrm{mV} \mathrm{s}^{-1}$.

at bare and p-ATT modified GC electrodes in $0.20 \mathrm{M}$ PB solution ( $\mathrm{pH}$ 5.0). In the first cycle, bare GC electrode showed two shoulder waves around $0.32 \mathrm{~V}$ and $0.45 \mathrm{~V}$ along with an oxidation peak at $0.51 \mathrm{~V}$ for AA, DOPAC and UA, respectively in a mixture (curve a). In the subsequent cycles, the oxidation peak currents of them were shifted to more positive potential. After 5 cycles, the oxidation peaks were appeared at 0.33 , 0.46 and $0.52 \mathrm{~V}$ with decreased peak currents (curve b). This divulged that bare GC electrode is not suitable for the determination of AA, DOPAC and UA in a mixture. On the other hand, the p-ATT modified electrode successfully separated the oxidation peaks of AA, DOPAC and UA and their oxidation peaks were appeared at $0.24,0.38$ and $0.51 \mathrm{~V}$, respectively (curve c). Further, the oxidation peaks of them were more stable at p-ATT modified electrode in the subsequent cycles (curve d). The oxidation peak potential difference between AA and DOPAC was $140 \mathrm{mV}$ and DOPAC and UA was 130 , which were more than enough for the simultaneous determination of AA, DOPAC and UA in a mixture. This indicated that the oxidation of AA, DOPAC and UA at p-ATT modified electrode is independent and therefore simultaneous or independent measurement of the three analytes is possible without any interference. It is well known that AA, DOPAC and UA were present as anonic forms in pH5.0. ${ }^{13,29,30}$ It is expected that the negatively charged AA, DOPAC and 
UA were electrostatically attracted by the positively charged back bone of the p-ATT film. ${ }^{24}$ Thus, enhanced oxidation peak currents were observed for them at modified electrode when compared to bare GC electrode. Similar suggestion was recently reported at $\operatorname{poly}\left(N, N^{\prime}-\right.$ dimethylaniline) modified boron-doped diamond electrode $^{11}$ and dithiobishexaneamine monolayer modified Au electrode. ${ }^{12}$

\subsection{Simultaneous determination of AA, DOPAC and UA using p-ATT modified electrode}

One of the objectives of the present study is to determine the concentrations of AA, DOPAC and UA simultaneously using p-ATT modified electrode. An accurate determination of these analytes is very important in the clinical point of view, because these analysts are coexisted in blood serum and urine. ${ }^{10}$ Figure 3 shows the differential pulse voltammograms (DPVs) obtained for the simultaneous determination of AA, DOPAC and $\mathrm{UA}$ at p-ATT modified electrode. It showed the oxidation peaks at $0.14,0.30$ and $0.44 \mathrm{~V}$ for $20 \mu \mathrm{M}$ AA, $2.5 \mu \mathrm{M}$ DOPAC and $10 \mu \mathrm{M} \mathrm{UA}$, respectively (curve a). Based on LSV results in figure 2, the order of sensitivity of these molecules at p-ATT modified electrode was found to be DOPAC $>$ UA $>$ AA. Thus, we have chosen $2.5 \mu \mathrm{M}$ DOPAC, $10 \mu \mathrm{M}$ UA and $20 \mu \mathrm{M}$ AA

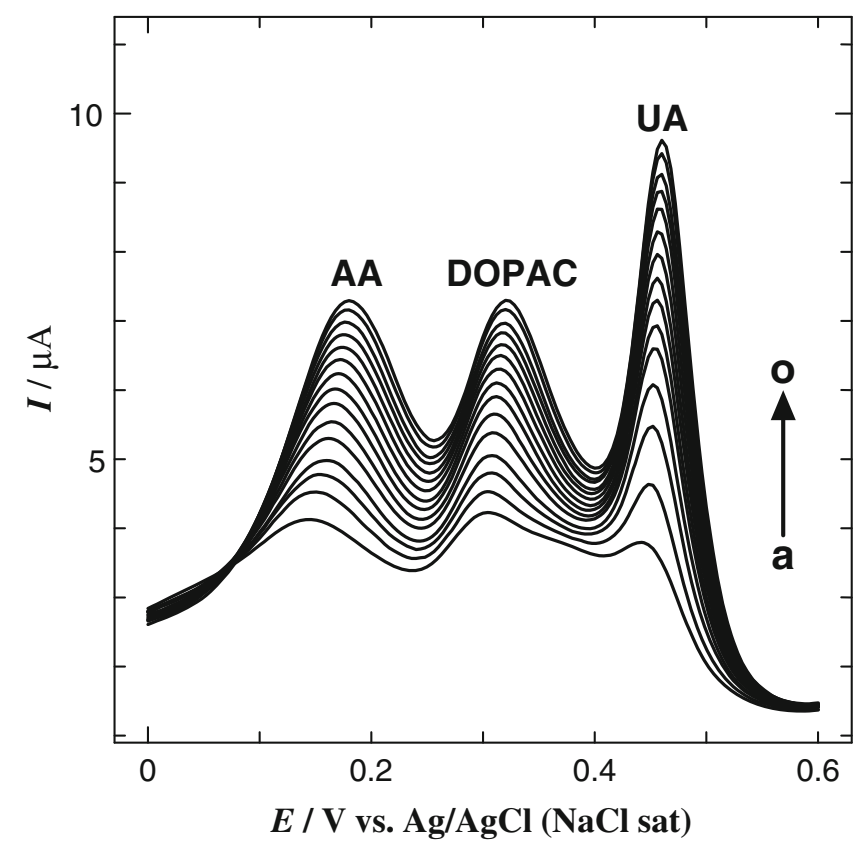

Figure 3. DPVs obtained for the increment of $20 \mu \mathrm{M} \mathrm{AA}$, $2.5 \mu \mathrm{M}$ DOPAC and $10 \mu \mathrm{M}$ UA in $0.20 \mathrm{M}$ PB solution at p-ATT modified GC electrode. Pulse width $=0.06 \mathrm{~s}$, amplitude $=0.05 \mathrm{~V}$, sample period $=0.02 \mathrm{~s}$ and pulse period $=$ $0.2 \mathrm{~s}$. as increments. The oxidation peak of UA remained same whereas a slight shift in the oxidation potentials of AA and DOPAC were observed for further addition of the respective analytes (curves $\mathrm{b}-\mathrm{o}$ ). When the concentration of AA was increased from 20 to $300 \mu \mathrm{M}$, DOPAC was increased from 2.5 to $37.5 \mu \mathrm{M}$ and UA was increased from 10 to $150 \mu \mathrm{M}$, the peak currents of AA, DOPAC and UA were increased linearly with a correlation coefficient of 0.9994, 0.9997 and 0.9992, respectively.

\subsection{Selective determination of DOPAC in the presence of $A A$ and $U A$}

The main intention of the present study is to determine the concentration of DOPAC in the presence of very high concentrations of AA and UA. It is wellknown that AA and UA are present along with DOPAC in our body fluids and further their concentrations are very much higher than that of DOPAC. ${ }^{31}$ Therefore, for the clinical point of view, the determination of DOPAC in the presence of high concentrations of AA and UA is very important. Figure 4 shows the DPVs obtained for the increment of $10 \mu \mathrm{M}$ DOPAC in the presence of $500 \mu \mathrm{M}$ each AA and UA. A very clear signal was observed for $10 \mu \mathrm{M}$ DOPAC in the presence of $500 \mu \mathrm{M}$

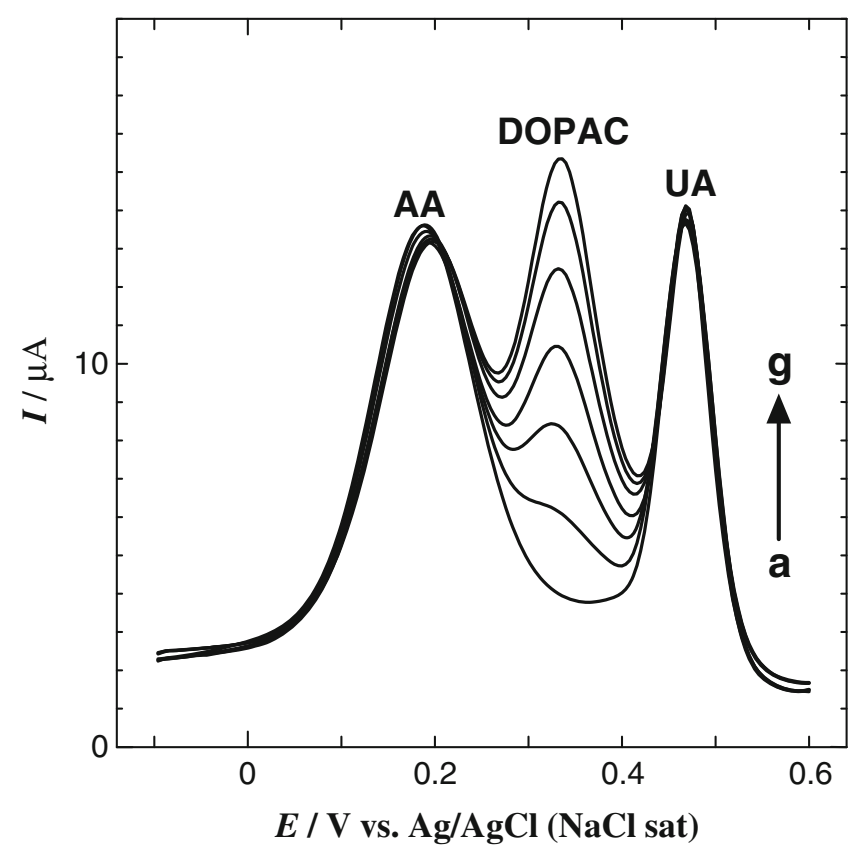

Figure 4. DPVs obtained for the increment of $10 \mu \mathrm{M}$ DOPAC to $500 \mu \mathrm{M}$ each AA and UA in $0.20 \mathrm{M}$ PB solution at p-ATT modified electrode (a) 0, (b) 10, (c) 20, (d) 30, (e) 40, (f) 50 and (g) $60 \mu \mathrm{M}$. Pulse width $=0.06 \mathrm{~s}$, amplitude $=0.05 \mathrm{~V}$, sample period $=0.02 \mathrm{~s}$ and pulse period $=$ $0.2 \mathrm{~s}$. 
each AA and UA in figure 4 (curve b), which revealed that the detection of very low concentration of DOPAC is possible even in the presence of 50-fold excess of each AA and UA. The increment of $10 \mu \mathrm{M}$ DOPAC to a solution of $500 \mu \mathrm{M}$ each AA and UA increases the current of DOPAC with a correlation coefficient of 0.9998 , respectively while the peak current of AA and UA remain unchanged. Usually, AA and UA are present 20 -fold excess than DOPAC in extracellular fluid. ${ }^{31}$ In the present study, we have determined DOPAC even in the presence of 50-fold excess of AA and UA. These results showed that p-ATT modified electrode is more suitable for practical applications.

\subsection{Amperometric determination of DOPAC along with $A A$ and $U A$}

Amperometric method was performed to examine the sensitivity of p-ATT modified electrode towards the detection of DOPAC individually and also along with $\mathrm{AA}$ and UA. Figure 5 depicts the amperometric $i-t$ curve for DOPAC at p-ATT modified electrode in a homogeneously stirred $0.20 \mathrm{M}$ PB solution at an applied potential of $+0.50 \mathrm{~V}$. The modified electrode showed the initial current response due to $40 \mathrm{nM}$ DOPAC and

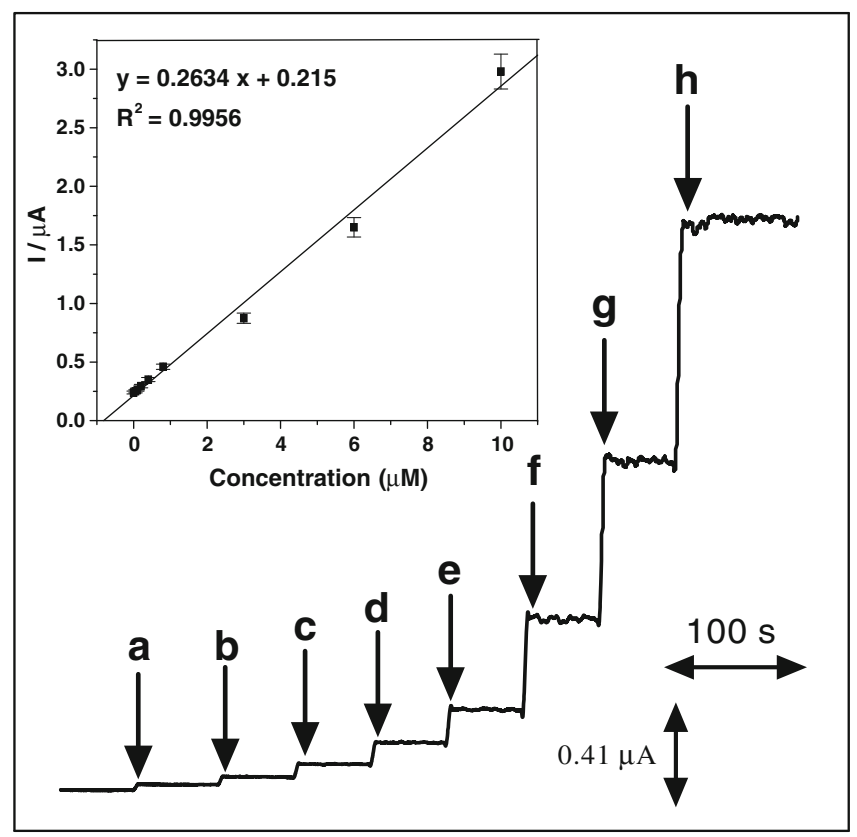

Figure 5. Amperometric $i-t$ curve for the determination of DOPAC at p-ATT modified electrode in $0.20 \mathrm{M}$ PB solution. Each addition increases the concentrations of DOPAC (a) 40, (b) 100, (c) 200, (d) 400, (e) 800, (f) 3000, (g) 6000 and (h) $10000 \mathrm{nM}$ at a regular interval of $50 \mathrm{~s} . E_{\text {app }}=+0.50 \mathrm{~V}$. further addition of $100 \mathrm{nM}$ DOPAC into the same solution with a sample interval of $50 \mathrm{~s}$, the current response was increased and a steady state current response was attained within $3 \mathrm{~s}$. Again the current response was increased for further addition of 200, 400, 800, 3000, 6000 and $10000 \mathrm{nM}$ DOPAC to the same solution with a sample interval of $50 \mathrm{~s}$. The amperometric current was linearly increased while increasing the concentration of DOPAC from $4.0 \times 10^{-8}$ to $1.0 \times 10^{-5}$ at p-ATT modified electrode with a correlation coefficient of 0.9956 and the detection limit was found to be $0.15 \mathrm{nM}$ (inset of figure 5).

The amperometric method was also performed to determine the concentration of DOPAC along with AA and UA. Figure 6 displays the amperometric current response for the alternative addition of AA, DOPAC and UA in $0.20 \mathrm{M}$ PB solution at an applied potential of $+0.60 \mathrm{~V}$. The p-ATT modified electrode showed the initial current response due to $75 \mathrm{nM}$ AA and addition of $40 \mathrm{nM}$ DOPAC to this solution with a sample interval of $50 \mathrm{~s}$, the current response was increased. The current response was again increased after the addition of $60 \mathrm{nM}$ UA to the same solution. The amperometric current of DOPAC does not change in the presence of AA and UA. Further, the observed systematic increase in the current responses due to the addition of AA, DOPAC and UA indicated that the determination of any

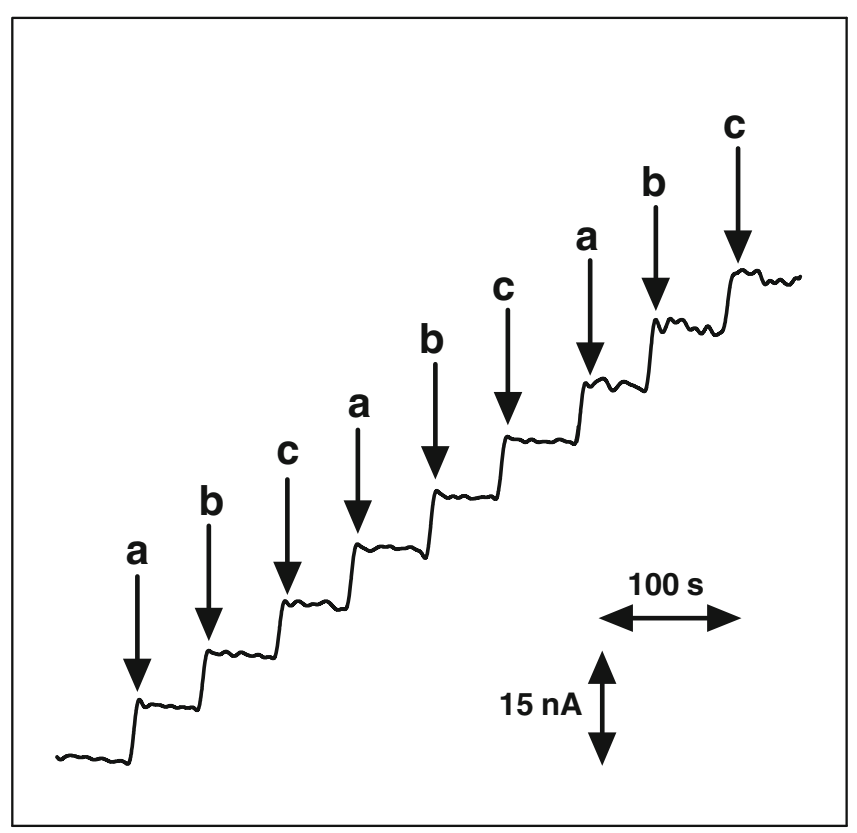

Figure 6. Amperometric $i-t$ curve for the alternative addition of AA, DOPAC and UA at p-ATT modified GC electrode in $0.20 \mathrm{M}$ PB solution. Each addition increases the concentration of (a) $75 \mathrm{nM} \mathrm{AA}$, (b) $40 \mathrm{nM}$ DOPAC and (c) $60 \mathrm{nM}$ $\mathrm{UA}$ at a regular interval of $50 \mathrm{~s}$. $E_{\text {app }}=+0.60 \mathrm{~V}$. 
one of the analytes is possible in the presence of other analytes using p-ATT modified electrode. We have estimated the current response for $75 \mathrm{nM}$ AA as $7.3 \mathrm{nA}$, $40 \mathrm{nM}$ DOPAC as $7.1 \mathrm{nA}$ and $60 \mathrm{nM}$ UA as $7.2 \mathrm{nA}$ from figure 6.

The sensitivity of $0.084 \mu \mathrm{A}$ at poly $\left(N, N^{\prime}\right.$-dimethylaniline) modified boron-doped diamond electrode, ${ }^{11}$ $0.016 \mu \mathrm{A}$ at short chain thiol/disulfides modified $\mathrm{Au}$ electrode $^{12}$ and $0.040 \mu \mathrm{A}$ at tyrosinase-conjugated polysaccharide hybrid film modified GC electrode ${ }^{32}$ per $\mu \mathrm{M}$ of DOPAC were reported. Further, the lowest detection limit of 400 and $3 \mathrm{nM}(S / N=3)$ were reported at single-wall carbon nanotubes ${ }^{17}$ and tyrosinase-conjugated polysaccharide hybrid film $^{32}$ modified GC electrodes, respectively. When compared to the reported modified electrodes, the present modified electrode showed the sensitivity of $0.18 \mu \mathrm{A}$ per $\mu \mathrm{M}$ with a lowest detection limit of $0.15 \mathrm{nM}(S / N=3)$ for DOPAC. To the best of our knowledge, this is the first report for the very high sensitivity and lowest detection limit for DOPAC.

\subsection{Anti-interference ability of the p-ATT film}

The anti-interference ability of the p-ATT film was tested towards the detection of DOPAC from various physiological interferents such as glucose, urea, oxalate, valine, alanine, phenylalanine, proline, glycine, $\mathrm{Ca}^{2+}, \mathrm{Mg}^{2+}$ and $\mathrm{Na}^{+}$by amperometric method. No change in the amperometric current response was observed for $40 \mathrm{nM}$ DOPAC in the presence of $100 \mu \mathrm{M}$ of aforesaid analytes. This revealed that the present modified electrode is highly selective towards the determination of DOPAC even in the presence of 2500-fold excess of common physiological interferents (figure not shown).

\subsection{Reproducibility and stability of the p-ATT film}

The DPVs for $0.25 \mathrm{mM}$ DOPAC in $0.20 \mathrm{M}$ PB solution were recorded for every $3 \mathrm{~min}$ interval to evaluate the stability of the p-ATT modified electrode. It was found that the oxidation peak current of DOPAC remained same with a relative standard deviation of $1.23 \%$ for 25 times repetitive measurements indicating that this electrode has a good stability. Further, to find out the reproducibility of the results, three different GC electrodes were modified with the p-ATT film and their response towards the oxidation of $0.50 \mathrm{mM} \mathrm{AA}$, UA and DOPAC was tested by 25 repeated measurements.
The separation between the voltammetric peaks of AADOPAC and DOPAC-UA were the same at all the three electrodes. The peak current obtained in the 25 repeated measurements of three independent electrodes showed a relative standard deviation of $1.21 \%$, confirming that the results are reproducible. The stability of the p-ATT film was also examined. While we keeping p-ATT modified electrode in $0.20 \mathrm{M}$ PB solution at room temperature, no apparent decrease in the current response of DOPAC was observed in first two days and $6.6 \%$ of current was decreased after 2 weeks. These results showed that the present modified electrode was very much stable and reproducible towards the determination of AA, DOPAC and UA.

It is worth to compare the determination of DOPAC at p-ATT modified electrode with the reported chemically modified electrodes. The fabrication of p-ATT film on GC electrode surface is very simple and less time consuming $(\sim 20 \mathrm{~min})$ when compared to reported modified electrodes for the determination of DOPAC. For example, for the preparation of tyrosinaseconjugated polysaccharide hybrid film modified GC electrode, $2 \mathrm{mg} / \mathrm{ml}$ chitosan solution and a $0.60 \mathrm{mg} / \mathrm{ml}$ tyrosinase solution mixed well under sonication. Then the $20 \mu \mathrm{L}$ aliquot of the composite solution was evenly cast onto a GC surface and dried overnight under room temperature. ${ }^{32}$ Similarly, for the preparation of functionalized self-assembled monolayer modified electrode, the $\mathrm{Au}$ was immersed into ethanol solution of $10 \mathrm{mM}$ dithiobishexaneamine and $0.5 \mathrm{mM}$ macrocylic nickel(II) complex for $12 \mathrm{~h}^{12}$

\section{Conclusions}

Highly sensitive determination of DOPAC in the presence of AA and UA using p-ATT modified GC electrode in $0.20 \mathrm{M}$ PB solution was reported for the first time. The bare $\mathrm{GC}$ electrode failed to resolve the voltammetric signals of AA, DOPAC and UA whereas p-ATT modified electrode successfully resolved the voltammetric signals of them. The modified electrode separated the voltammetric signals of AA, DOPAC and UA with potential differences of $140 \mathrm{mV}$ between $\mathrm{AA}$ and DOPAC and $130 \mathrm{mV}$ between DOPAC and UA. The oxidation currents of AA, DOPAC and UA were remarkably increased at p-ATT modified electrode when compared to bare GC electrode due to the presence of strong electrostatic attraction between positively charged p-ATT film and negatively charged analytes. The modified electrode exhibited an excellent sensitivity and selectivity towards DOPAC even in the 
presence of 50-fold excess of each AA and UA. The detection of $40 \mathrm{nM}$ DOPAC was achieved at modified electrode using amperometric method. The amperometric current response was increased linearly with increasing DOPAC concentration from $4.0 \times 10^{-8}$ to $1.0 \times$ $10^{-5} \mathrm{M}$ and the detection limit was found to be $150 \mathrm{pM}$ $(S / N=3)$.

\section{Supplementary information}

For figure S1 see www.ias.ac.in/chemsci website.

\section{Acknowledgements}

Palraj Kalimuthu thanks the Council of Scientific and and Industrial Research (CSIR), New Delhi, for the award of Senior Research Fellowship (09/715(0008)/ 2008/EMR-I). Financial support from the Department of Science and Technology, New Delhi under Nanomission (No.SR/NM/NS-28/2008) is gratefully acknowledged.

\section{References}

1. Anderson G M, Riddle M A, Hoder E L, Feibel F C, Shaywitz B A, Cohen D J 1988 J. Neurol. Neurosurg. Psychiatry $\mathbf{5 1} 1100$

2. Thiffault C, Langston J W and Monte D A D 2003 Exp. Neuro. 18173

3. D'Angio M and Scatton B 1989 Neurosci. Lett. 96223

4. Chase T N 1980 Neurochemical alterations in Parkinson's disease (ed) J H Wood, Neurobiology of cerebrospinal fluid (New York: Plenum), pp. 207

5. LeWitt P A 1993 Adv. Neurol. 60544

6. Thogi H, Abe T, Saheki M, Yamazaki K and Murata T 1997 J. Neural. Transm. 104441

7. Wightman R M, May L J and Michael A C 1988 Anal. Chem. 60 769A

8. Stamford J A, Palij P, Davidson C and Trout S J 1995 Bioelectrochem. Bioenerg. 38289
9. Valentini F, Orlanducci S, Terranova M L, Amine A and Palleschi G 2004 Sens. Actuators B 100117

10. Salimi A, MamKhezri H and Hallaj R 2006 Talanta 70 823

11. Roy P R, Saha M S, Okajima T, Park S G, Fujishima A and Ohsaka T 2004 Electroanalysis 161777

12. Raj C R and Ohsaka T 2002 Electroanalysis 14679

13. Raj C R and Behera S 2005 J. Electroanal. Chem. $\mathbf{5 8 1} 61$

14. Raj C R and Ohsaka T 2001 Chem. Lett. 30670

15. Kalimuthu P and John S A 2008 J. Electroanal. Chem. 617164

16. Maldonado S, Morin S, and Stevenson K J 2006 Analyst 131262

17. Wang J, Li M, Shi Z, Li N and Gu Z 2001 Electrochim. Acta $\mathbf{4 7} 651$

18. Liu A, Honma I and Zhou H 2005 Electrochem. Commun. 7233

19. Curulli A, Valentini F, Padeletti G, Viticoli M, Caschera D and Palleschi G 2005 Sens. Actuators B 111-112 441

20. Yeung P K F, Buckley S J, Pedder S C J and Dingemanse J 1996 J. Pharm. Sci. 85451

21. Adcock J L, Barnett N W, Costin J W, Francis P S, and Lewis S W 2005 Talanta 67585

22. Drujan B D, Alvarez N and Borges J M D 1966 Anal. Biochem. 158

23. Weisel F A 1975 Neurosci. Lett. 1219

24. Kalimuthu P and John S A 2009 Electrochem. Commun. 11367

25. Kalimuthu P and John S A 2009 Bioelectrochemistry 7713

26. Kalimuthu P and John S A 2009 Biosens. Bioelectron. 243575

27. Kalimuthu P and John S A 2009 Anal. Chim. Acta 64797

28. Kalimuthu P and John S A 2009 Electrochem. Commun. 111065

29. Giz M J, Duong B and Tao N J 1999 J. Electroanal. Chem. $\mathbf{4 6 5} 72$

30. Zhao H, Zhang Y and Yuan Z 2001 Anal. Chim. Acta 441117

31. Crespi F, Martin K F and Marsden C A 1988 Neuroscience 27885

32. Liu A, Honma I and Zhou H 2005 Biosens. Bioelectron. 21809 